\title{
Temperature compensation of electrical conductivity in glacial meltwaters
}

\author{
C. C. SMART \\ Department of Geography, University of Western Ontario, London, Ontario N6A 5C2, Canada
}

\begin{abstract}
Temperature compensation built into many conductivity meters becomes inaccurate in low-temperature waters typical of glacial melt streams. Experiments using simulated glacial waters show a linear dependence of electrical conductivity on temperature from $0.3^{\circ}$ to $25^{\circ} \mathrm{C}$. The slope of the temperatureconductivity relation is linearly dependent on the conductivity of the solution, allowing a numerical or analytical temperature correction to be made. To minimize error introduced by temperature compensation, measurements of electrical conductivity in glacial streams should be corrected to a low standard temperature, and $0^{\circ} \mathrm{C}$ is suggested.
\end{abstract}

\section{INTRODUGTION}

The electrical conductivity of glacial meltwaters provides a simple, immediate and useful surrogate for the total concentration of dissolved ions, especially in sites where carbonates are the dominant species. As such, it has been widely employed as a tracer of water source and routing through glacial systems (see Fenn (1987) for a recent review).

Temperature exerts a significant positive influence on electrical conductivity. Most commercial conductivity meters simultaneously measure temperature and conductivity, and typically apply a correction factor of $2 \%{ }^{\circ} \mathrm{C}^{-1}$ to give electrical conductivity at standard temperatures of $20^{\circ}$ or $25^{\circ} \mathrm{C}$. This implies that compensation slopes depend simply on measured electrical conductivity. There are several problems with this style of temperature compensation. First, the correction factor is considered "typical" for surface waters but actually depends upon ionic composition of waters (Hemm, 1982). Secondly, Østrem (1964) and Collins (1977) suggested that correction factors also depend on temperature and are higher at lower temperatures. Finally, any compensation errors will be particularly serious in cold glacial waters which need considerable adjustment.

As a result of these problems, following the recommendation of Collins (1977), it has become common not to apply temperature compensation in glaciological studies (Fenn, 1987, p. 382). This may be inconsequential where temperatures are consistently close to $0^{\circ} \mathrm{C}$ and electrical conductivities are highly variable. However, many glacial streams exhibit diurnal and episodic temperature variations, which confuse chemical and thermal conductivity effects.

Recently, Calles and Calles (1990) showed that electrical conductivity of samples of natural surface water varied linearly with temperatures above $3^{\circ} \mathrm{C}$ and could be described by

$$
E C_{\mathrm{T}}=b T+d
$$

where $E C_{\mathrm{T}}$ is electrical conductivity at temperature $T$, and $b$ and $d$ are linear regression parameters with $d$ equivalent to $E C_{0}$, the electrical conductivity at $0^{\circ} \mathrm{C}$.

The slope $b$ increased linearly with the base conductivity of the solution allowing them to define

$$
E C_{0}=f E C_{25}+k
$$

where $E C_{0}$ and $E C_{25}$ are electrical conductivities estimated from Equation (1) for a number of water samples. They suggested that accurate temperature compensation could best be obtained using

$$
E C_{25}=\frac{25 E C_{\mathrm{T}}-k(25+T)}{25 f+T(1-f)} .
$$

Proximal glacial stream temperatures are generally close to $0^{\circ} \mathrm{C}$, but little further from the glacier may vary by perhaps $10^{\circ} \mathrm{C}$ in $1 \mathrm{~d}$. Some form of temperature compensation is therefore desirable, although inaccurate temperature compensation to $25^{\circ} \mathrm{C}$ may introduce significant errors. Compensation to a much lower standard temperature will constrain errors and allow crude comparison with extant uncompensated data. $E C_{0}$ appears as parameter $d$ in Equation (1) and, although "fictive" provides a standard temperature very close to subglacial water temperatures. Arguments may be made for more realistic standard temperatures such as $1^{\circ} \mathrm{C}$ or even $4^{\circ} \mathrm{C}$ (the maximum density of water) but they are not explicit in the model.

On this basis, the effect of the $0-10^{\circ} \mathrm{C}$ temperature range on electrical conductivity was studied for simulated glacial waters. The first objective was to investigate temperature-conductivity relations below $0^{\circ} \mathrm{C}$, the second to develop a robust method of temperature compensation to $0^{\circ} \mathrm{C}$. 


\section{EXPERIMENTAL METHOD}

Simulated glacial meltwaters were made up using distilled water and the coarse clay-sized fraction of fresh carbonate-rich till collected from Small River Glacier, British Columbia. The water was not degassed, allowing "natural" till dissolution to occur. A suspension of $1000 \mathrm{mg} \mathrm{l}^{-1}$ was made up and stored for several weeks to allow equilibration. Aliquots were then used to make up more dilute suspensions of $0.5,1$ and $100 \mathrm{mgl}^{-1}$. In addition to pure distilled water, tap water was used to make up suspensions of 0 and $10 \mathrm{mg} \mathrm{l}^{-1}$ concentrations.

The mixtures were stored for about $1 \mathrm{~d}$ to allow chemical equilibration and cooled to close to $0^{\circ} \mathrm{C}$. Samples were then stirred in an insulated container and allowed to warm passively as temperature and electrical conductivity were measured. Temperatures were determined using a T-type (copper-constantan) thermocouple attached to a Campbell Scientific CR21X Micrologger with a Fenwall Electronics UUT51J1 thermistor reference thermometer. Tests suggest measurements are accurate to $0.1^{\circ} \mathrm{C}$ and somewhat more precise. Conductivites were measured using an uncompensated Great Lakes Instruments 31031 conductivity probe attached to the data logger. Measurements were accurate to $\pm 0.5 \mathrm{mS} \mathrm{m}^{-1}$ with precision better than $\pm 0.1 \mathrm{mS} \mathrm{m}^{-1}$. Experiments ran for 6-12 h, with measurements every $5 \mathrm{~s}$ stored as $1 \mathrm{~min}$ averages. Initial measurements in each run showed differential adjustment of the temperature and conductivity sensors (e.g. Fig. 1), regardless of initial temperature and were discarded from analysis. In a few cases, melting ice caused a slight decrease in conductivity with no temperature change. As a result, data sets typically ran from about $0.3^{\circ}$ to $25^{\circ} \mathrm{C}$.

A further experiment investigated the effect of

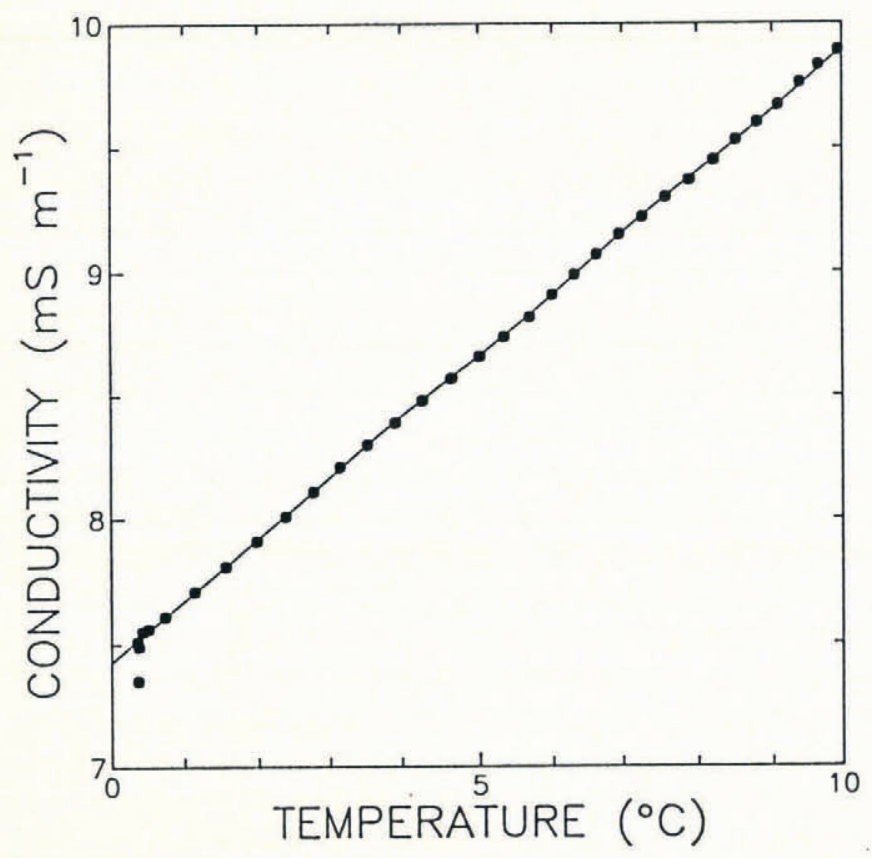

Fig. 1. Sample plot of electrical conductivity against temperature for $1.0 \mathrm{mgl}^{-1}$ sediment in distilled water. Only every tenth data point is marked. Note anomalous points during initial equilibration. These were excluded from the analysis.

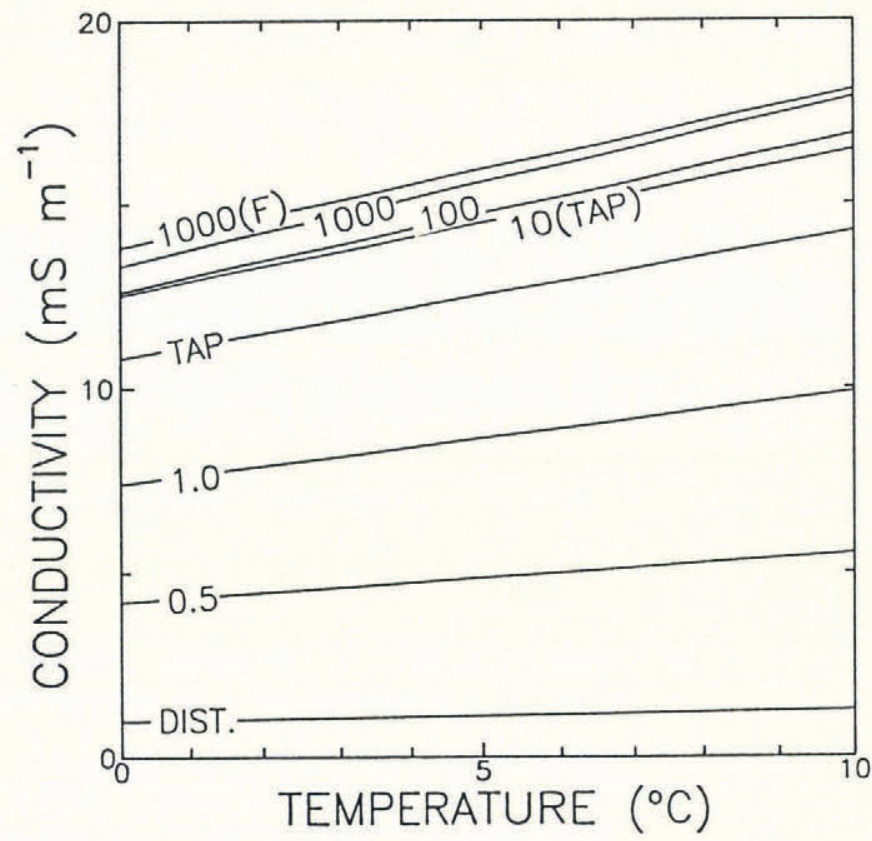

Fig. 2. Collective results of all experiments. The lines are described by Equation (1) and summarized in Table 1. Lines represent unfiltered distilled-water mixtures unless marked "Tap" for tap water. Figures give sediment concentration in $\mathrm{mgl}^{-1} .1000(\mathrm{~F})$ indicates a $1000 \mathrm{mg} \mathrm{l}^{-1}$ distilled-water sample filtered before analysis.

suspended sediment on the results. A $1000 \mathrm{mgl}^{-1}$ sample was vacuum-filtered through a $0.2 \mu \mathrm{m}$ millipore celluloseacetate filter before being analysed. A $1000 \mathrm{mg} \mathrm{l}^{-1}$ mixture was homogenized and left unstirred at constant temperature and its conductivity measured as sediment settled out.

\section{RESULTS AND ANALYSIS}

In all cases, a linear dependence of electrical conductivity on temperature was observed within (and well beyond) the $10^{\circ} \mathrm{C}$ temperature range (Figs 1 and 2) with correlation coefficients over 0.999. Contrary to Collins (1977), there is no evidence for anomalous behaviour below $3^{\circ} \mathrm{C}$. The results are thus consistent with Calles and Calles (1990), although their experiments addressed natural non-glacial waters at temperatures higher than $3^{\circ} \mathrm{C}$.

The full range of samples in Figure 2 shows conductivities at $0^{\circ} \mathrm{C}$ ranged from 0.97 to $13.4 \mathrm{mS} \mathrm{m}^{-1}$ depending on sediment concentration. In all mixtures there was excess suspended sediment and presumably equilibration with atmospheric $\mathrm{PCO}_{2}$, so this may reflect limiting quantities of highly soluble minerals such as gypsum and calcite.

The sediment-settling experiment showed no measurable evolution of electrical conductivity over $24 \mathrm{~h}$ as the sample became visually clear. Thus, the suspended sediment itself was not influencing the measured electrical conductivity. However, the filtered sample showed an increase (of $4 \%$ ) in electrical conductivity (cf. Collins, 1977), indicating that vacuum filtering increases ionic concentration despite degassing decreas- 
ing solution $\mathrm{PCO}_{2}$. Further filtering had little effect. This may be of concern to glacier hydrochemists, who necessarily filter their samples prior to analysis.

The conventional electronic correction factors expressed as $\%{ }^{\circ} \mathrm{C}^{-1}$ varied from 2.73 to 3.01 (Table 1), somewhat higher than the traditional value of $2 \%{ }^{\circ} \mathrm{C}^{-1}$. The unfiltered distilled-water experiments indicate a

Table 1. Results of electrical conductivity experiments with conventional temperature-correction factor, and intercept (d) and coefficient (b) of best-fit line

\begin{tabular}{crrrl} 
Solvent & Sediment & Correction & $d\left(=E C_{0}\right)$ & $b$ \\
& $\mathrm{mg} \mathrm{l}^{-1}$ & $\%{ }^{\circ} \mathrm{C}^{-1}$ & $\mathrm{mS} \mathrm{m}^{-1}$ & $\mathrm{mS} \mathrm{m}^{-1}{ }^{\circ} \mathrm{C}^{-1}$ \\
\hline $\begin{array}{c}\text { Distilled } \\
\text { water }\end{array}$ & 0.0 & 2.73 & 0.971 & 0.0300 \\
$\begin{array}{c}\text { Distilled } \\
\text { water }\end{array}$ & 0.5 & 2.78 & 4.20 & 0.132 \\
$\begin{array}{c}\text { Distilled } \\
\text { water }\end{array}$ & 1.0 & 2.92 & 7.42 & 0.248 \\
$\begin{array}{c}\text { Distilled } \\
\text { water }\end{array}$ & 100.0 & 2.98 & 12.6 & 0.430 \\
$\begin{array}{c}\text { Distilled } \\
\text { water }\end{array}$ & 1000.0 & 3.01 & 13.3 & 0.460 \\
$\begin{array}{c}\text { Distilled } \\
\text { water }\end{array}$ & 1000.0 & 2.76 & 13.8 & 0.433 (filtered) \\
$\begin{array}{c}\text { Tap } \\
\text { water }\end{array}$ & 0.0 & 2.81 & 10.8 & 0.345 \\
$\begin{array}{c}\text { Tap } \\
\text { water }\end{array}$ & 10.0 & 2.80 & 12.5 & 0.397 \\
\hline
\end{tabular}

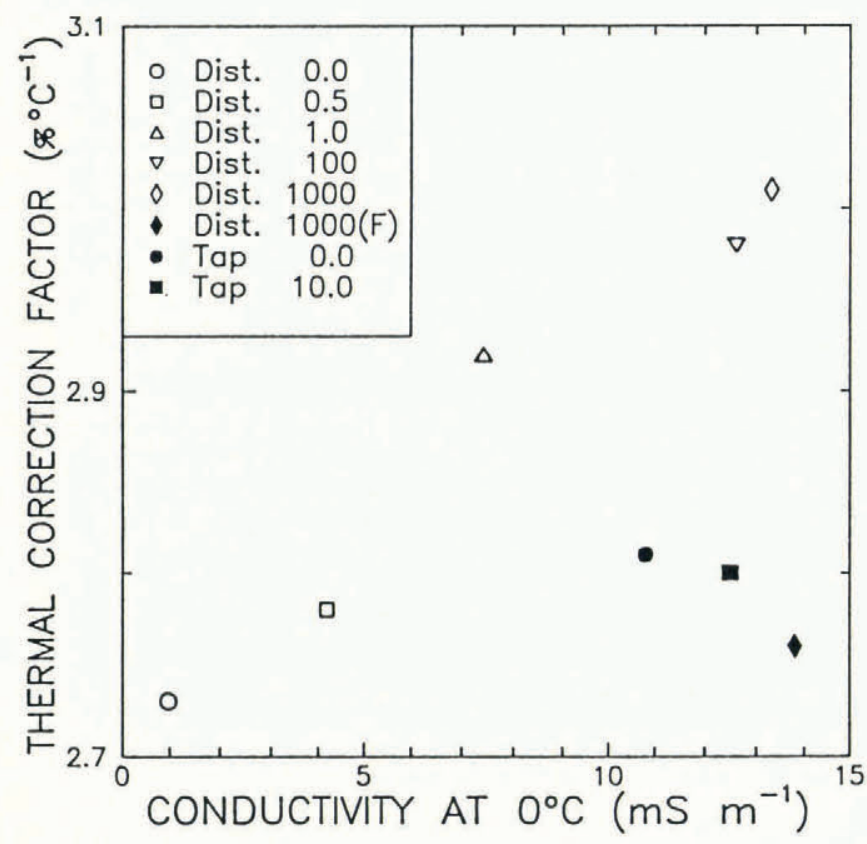

Fig. 3. Conventional electronic conductivity correction factors plotted against base conductivity $\left(d=E C_{0}\right)$. Key indicates water type, sediment concentration in $\mathrm{mg}^{-l}$ and filtration $(F)$. positive relationship between correction factor and base conductivity (Fig. 3), suggesting that for consistent ionic composition the correction factor can be inferred from conductivity. However, tap water and the filtered-water experiments lie well off this relationship, limiting the applicability of this approach. (This also suggests that the enhancement of electrical conductivity during filtration is associated with a change in chemical composition, possibly by ion exchange.)

For each sample, simple linear regression was used to establish $b$ and $d$ from Equation (1) above. The results are listed in Table 1. The coefficient $b$ showed a remarkable linear relation to $d$ such that $\{b\}=0.331\{d\}-0.0312$ with $r^{2}$ of 0.991 (Fig. 4), despite differences in water composition. Thus, the slope $b$ of the compensation can be determined from the base conductivity $E C_{0}(=d)$. Crude experiments with water samples from Small River Glacier appear to confirm the result. This apparently robust relationship can be used to solve for $E C_{0}$ given any pair of $E C_{\mathrm{T}}$ and $T$ using iterative estimates of $b$ from $E C_{x}$, where $E C_{x}$ indicates $E C_{\mathrm{T}}$ initially and $E C_{0}$ at convergence.

The equivalent analytical correction (Equation (3)) used by Calles and Calles (1990) is perhaps a more elegant method. It can be modified to solve for $E C_{0}$ as follows

$$
E C_{0}=\frac{25 E C_{\mathrm{T}}+\left(k \frac{T}{f}\right)}{25+T\left(\frac{1}{f}-1\right)} .
$$

My data produce values of $f=0.544$ and $k=0.0747$ from Equation (2) and this gives identical results to the iterative method I have employed. Figure 4 of Calles and Calles (1990, p.677) implies values of $f=0.57$ and $k=-0.393$, suggesting a simple fairly consistent ratio may underlie the relationship. Corrections to data measured in $\mu \mathrm{S} \mathrm{cm}^{-1}$ will require an increase of $k$ by a factor of 10 . Compensation to $25^{\circ} \mathrm{C}$ may be achieved using Equation (3) above from Calles and Calles.

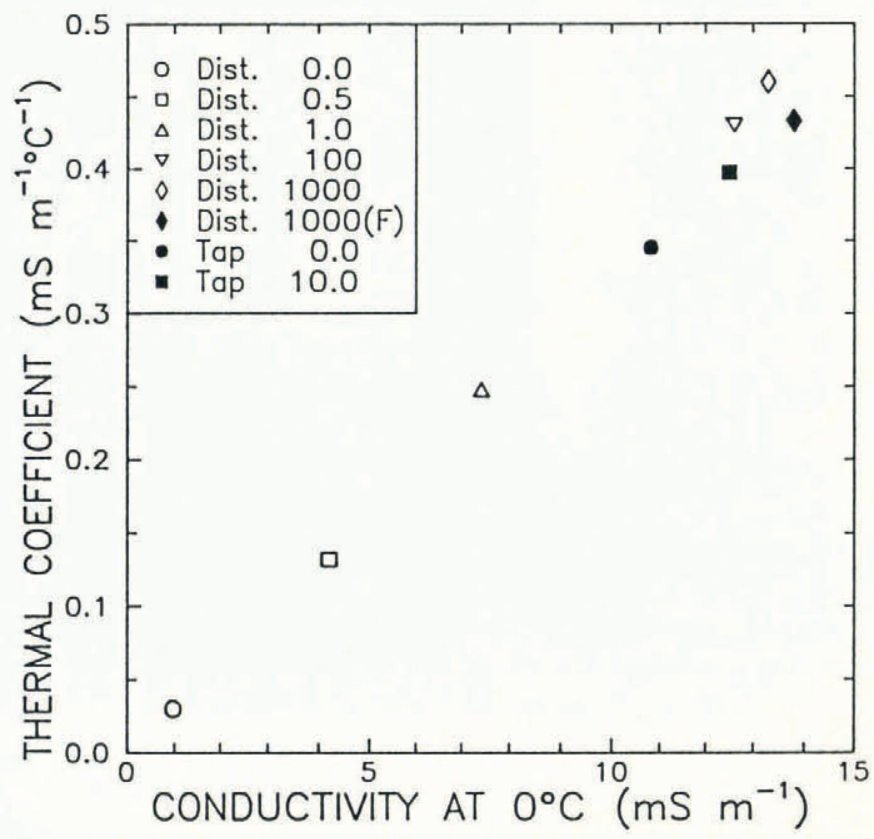

Fig. 4. Thermal coefficient (b) versus base conductivity $\left(d=E C_{0}\right)$. (Key as for Figure 3.) 


\section{CONCLUDING REMARKS}

In most cases, it is probably desirable to undertake temperature compensation on electrical conductivity measurements in glacial melt streams because temperature-controlled and underlying conductivity signals are usually very similar and difficult to separate. Instrumental temperature compensation may not be accurate at temperatures far removed from the standard temperature. The $2 \%{ }^{\circ} \mathrm{C}^{-1}$ method appears to be based on electronic convenience and is inappropriate for cold waters. It is the inaccurate compensation rather than any real effect which accounts for apparent conductivity errors in low-temperature waters (cf. Collins, 1977). Indeed, compensation in many conductivity meters is typically stated to be from $5^{\circ}$ to $40^{\circ} \mathrm{C}$.

Most electronic recording systems for electrical conductivity can be simply modified to record temperature. In clear water, the temperature sensor should be shaded to avoid radiative heating. Correction to $0^{\circ} \mathrm{C}$ provides data most comparable to uncorrected data and minimizes the effect of any error. The iterative or analytical (Equation (4)) methods are equally effective, both requiring minimal computation.

Values of $f$ and $k$ can be established from a representative range of water samples where differences in underlying chemical composition are anticipated. However, the compensation parameters will probably not vary significantly in terms of the overall reliability of the raw data. Measurements on small, clear streams some distance below the glacier snout and during rainfall events appear to require the maximum compensation.

\section{ACKNOWLEDGEMENTS}

The Natural Sciences and Engineering Research Council of Canada have supported this work through operating grants to the author and a studentship to $\mathrm{Mr} \mathrm{B}$. Fowle, who ably assisted in the laboratory experiments.

\section{REFERENCES}

Calles, B. and U. M. Calles. 1990. Temperature correction of electrical conductivity values. Earth Surface Processes and Landforms, 15, 673-678.

Collins, D.N. 1978. Hydrology of an Alpine glacier as indicated by the geochemical composition of meltwater. Z. Gletscherkd. Glazialgeol., 13(1/2), 1977, 219238.

Fenn, C. R. 1987. Electrical conductivity. In Gurnell, A. M. and M.J. Clark, eds. Glaciofluvial sediment transfer: an alpine perspective. Chichester, etc., John Wiley and Sons, 377-414.

Hemm, J.D. 1982. Conductance: a collective measure of dissolved ions. In Minear, R. A. and L.H. Keith, eds. Water analysis. Vol. 1. Inorganic species. Part 1. New York, Academic Press.

Østrem, G. 1964. A method of measuring water discharge in turbulent streams. Geogr. Bull. 21, 21-43.

The accuracy of references in the text and in this list is the responsibility of the author, to whom queries should be addressed. 